\title{
Passaging impact of H9N2 avian influenza virus in hamsters on its pathogenicity and genetic variability
}

\author{
Houssam A Shaib ${ }^{1}$, Nelly Cochet $^{2}$, Thierry Ribeiro ${ }^{3}$, Afif M Abdel Nour ${ }^{3,4}$, Georges Nemer ${ }^{6}$, Esam \\ Azhar $^{4,5}$, Archana lyer ${ }^{7}$, Taha Kumosani ${ }^{7}$, Steve Harakeh ${ }^{4}$, Elie K Barbour ${ }^{1,8}$ \\ ${ }^{1}$ Department of Animal and Veterinary Sciences, Faculty of Agricultural and Food Sciences, American University of \\ Beirut, Beirut, Lebanon \\ ${ }^{2}$ Department of Biological Engineering, Université de Technologie de Compiègne, Compiègne, France \\ ${ }^{3}$ Institut Polytechnique LaSalle Beauvais, Beauvais, France \\ ${ }^{4}$ Special Infectious Agents Unit-Biosafety Level 3, King Fahd Medical Research Center, King Abdulaziz University, \\ Jeddah, Saudi Arabia \\ ${ }^{5}$ Medical Laboratory Technonology Department, Faculty of Applied Medical Sciences, King Abdulaziz University, \\ Jeddah, Saudi Arabia \\ ${ }_{7}^{6}$ Department of Biochemistry, Faculty of Medicine, American University of Beirut, Beirut, Lebanon \\ ${ }^{7}$ Department of Biochemistry, King Abdulaziz University, Jeddah, Saudi Arabia \\ ${ }^{8}$ Adjunct Professor, Biochemistry Department, Faculty of Science, King Fahd Medical Research Center, King \\ Abdulaziz University, Jeddah, Saudi Arabia
}

\begin{abstract}
Introduction: Avian influenza viruses of the H9N2 subtype have been reported to cause human infections. This study demonstrates the impact of nasal viral passaging of avian H9N2 in hamsters on its cross species-pathogenic adaptability and variability of amino acid sequences of the hemagglutinin (HA) and neuraminidase (NA) stalk.

Methodology: Three intranasal passagings of avian H9N2 in hamsters P1, P2, and P3 were accomplished. Morbidity signs and lesions were observed three days post viral inoculation. The HA test was used for presumptive detection of H9N2 virus in the trachea and lungs of the hamsters challenged with the differently passaged viruses. Different primers were used for PCR amplification of the HA1 and NA stalk regions of the differently passaged H9N2 viruses, followed by sequence alignment.

Results: The morbidity signs indicated low pathogenicity of the differently passaged H9N2 viruses in hamsters. The frequency of gross and microscopic lesions in the tracheas and lungs were insignificantly different among hamsters challenged with the differently passaged H9N2 viruses $(\mathrm{p}>0.05)$. There was $100 \%$ similarity in the amino acid sequence of the HA gene of most passaged viruses. The amino acid sequence of the neuraminidase in the third passaged H9N2 virus recovered from lungs showed a R46P mutation that might have a role in the pathogenic adaptability of $\mathrm{P} 3$ viruses in hamsters' lungs.

Conclusions: The apparent adaptation of avian H9N2 virus to mammalian cells is in agreement with the World Health Organization's alertness for a possible public health threat by this adaptable virus.
\end{abstract}

Key words: Avian influenza-H9N2 virus; pathogenic adaptability; hamsters; Hemagglutinin (HA); Neuraminidase (NA) stalk; Passages

J Infect Dev Ctries 2014; 8(5):570-580. doi:10.3855/jidc.4023

(Received 22 July 2013 - Accepted 10 December 2013)

Copyright (C) 2014 Shaib et al. This is an open-access article distributed under the Creative Commons Attribution License, which permits unrestricted use, distribution, and reproduction in any medium, provided the original work is properly cited.

\section{Introduction}

Avian influenza viruses of the H9N2 subtype are widely circulating in avian species and have been reported to cause infections in humans. Interspecies transmission of H9N2 avian influenza (AI) viruses is well documented in the literature [1-3]. Major poultry H9N2 virus outbreaks originated from viruses harbored by shorebirds and wild ducks, while various birds and mammals such as quails and ferrets are thought to play a major role in the reassortment of new
AI strains that enables them to cross the interspecies barrier [2,4-7]. It has been documented that $16 \%$ of quails in Hong Kong tested positive for H9N2 viruses containing an H5N1like internal genome. Moreover, H6N1 and H9N2 viruses have been reported to be cocirculating in quails of Hong Kong, and they both share common genes with the H5N1 viruses that have caused human fatalities and poultry outbreaks in Southeast Asia [2]. 
The isolation of H9N2 viruses from swines in Hong Kong in 1998 raised concerns about the potential of this virus to be transmitted to humans, since both hosts have the same type of sialic acid (SA) receptors for avian influenza viruses [3]. Unfortunately, this prediction became a reality in 1999, when the H9N2 virus was isolated from seven patients in different provinces of China [1].

The continuous circulation of H9N2 viruses in Asia and worldwide [8-11] triggered scientists to focus on understanding the molecular changes in various genes from different strains that might lead to interspecies barrier crossing. Consequently, several animal models using mice, ferrets, and hamsters have been used to understand the H9N2 virus pathogenesis, tissue tropism, and host specificity or adaptability [1214].

Hamsters offered a good model for studying the reassortment of AI viruses. Hamsters can be infected with avian influenza viruses and transmit the viruses to uninfected animals. The upper and lower respiratory tracts and digestive system of hamsters are characterized by the presence of $\alpha-2,3$ and $\alpha-2,6$ sialic acid used by AI viruses as primary receptors $[13,15]$. Avian influenza viruses preferentially bind to $\alpha-2,3$ SA receptors [14,16-18], while human AI viruses bind to $\alpha-2,6$ SA receptors [19]. The adaptation of avian influenza $\mathrm{A}$ viruses to mammalian cells is dictated by a series of modifications in the viral internal genes, specifically those coding for hemagglutinin (HA) at the cleavage site and neuraminidase stalk (NA); such modifications enable the virus to recognize and bind to $\alpha-2,6 \mathrm{SA}$ receptors, inducing antibody responses in humans $[9,20]$.

At the HA gene level of $\mathrm{H} 9$ viruses, the literature documents the presence of glutamine at position 226 in avian viruses, while human and mammalian viruses have leucine at this position [1,11]. In addition, the loss of glycosylation site at positions Asn-11, Asn-94, and Asn-198, close to the receptor binding site at the C-terminus of HA of human viruses, may affect the receptor binding characteristics, thus increasing the pathogenicity of these viruses.

It is worth noting that among all of the isolated avian and human H9N2 viruses, two human isolates, namely A/Hong Kong/1073/99 H9N2 and A/Hong Kong/1074/99, and one quail isolate (Qa/HK/GI/97) had the same amino acid combination of His-191, Gln198 and Leu-234 in their hemagglutinin protein [1]. This combination was not found in the two reported Lebanese quail isolates of the H9N2 virus, namely
A/quail/Lebanon/273/2010

and

A/quail/Lebanon/272/2010 [21].

At the neuraminidase stalk (N2) level, mammalian H9N2 viruses have been characterized by deletion of two amino-acids at the 38 and 39 positions. The absence of a glycosylation site at position 402 of the $\mathrm{N} 2$ was a characteristic of the two human H9N2 virus isolates, thus differentiating them from the $\mathrm{Qa} / \mathrm{HK} / \mathrm{GI} / 99$ isolate of quails $[1,11]$.

Other internal viral proteins, such as the nonstructural protein (NS) [1] and the polymerase basic protein $(\mathrm{PB})$,specifically the $\mathrm{PB} 2[6,15]$, may have a role in determining the host range of avian influenza viruses; it is worth noting that the role of the matrix protein has not yet been established in host range specificity.

This study aimed to assess the impact of in vivo viral passaging of an original H9N2 virus isolated from poultry on its pathogenic adaptability to hamsters, and the relatedness of this adaptation to the variability of the amino acid sequence of the HA and N2 stalk proteins.

\section{Methodology}

\section{Original virus}

The original virus (P0), Lebanon1/H9N2, is a mildly pathogenic H9N2 virus that was isolated from a broiler chicken and propagated in the allantoic membranes of nine-day-old chicken embryos. The virus was subtyped as $\mathrm{H} 9 \mathrm{~N} 2$ at the Animal and Veterinary Sciences Department of the AmericanUniversity of Beirut, and its type was confirmed by the Central Veterinary Laboratory in Weybridge, UK.

\section{H9N2 passaging in hamsters}

The hamsters used in this study were influenza naïve prior to the initiation of the experiment. In studying the effect of each of the three differently passaged strains, experimental $(\mathrm{n}=10)$ and control hamsters $(n=10)$ were distributed in four separate cages, with five hamsters per cage. The experimental and the control hamsters were kept in two separate isolation rooms. The ten experimental fourweekold hamsters were intranasally challenged with the original $\mathrm{H} 9 \mathrm{~N} 2 \mathrm{AI}$ virus (P0), at two hemagglutination (HA) units $/ 50 \mu \mathrm{L}$ inoculum per hamster. The other 10 control hamsters were left free from any viral challenge. Following the first passage (P1), an individual presumptive detection of the hemagglutinating H9N2 virus from homogenates of tracheas and lungs of the experimental and control 
hamsters was assessed three days post inoculation using the hemagglutination (HA) test [22]. Lung homogenates with HA activity were pooled in equal volume, and the pool was used as an inoculum for a second passage of the H9N2 virus in another ten fourweek-old hamsters (P2), leaving 10 hamsters as controls. The inoculum used was adjusted to two hemagglutination (HA) units $/ 50 \mu \mathrm{L}$ inoculum per hamster. The same recovery protocol was used for P2 and P3 passages. The H9N2 viral detection in homogenate pools of tracheas or lungs of hamsters was confirmed by PCR amplification of the conservative matrix gene of the type A influenza virus.

Approval of the Institutional Animal Care and Use Committee at the Medical School of the American University of Beirut was obtained before the initiation of this study.

\section{Pathogenic adaptability assessment in hamsters}

Mortality and morbidity assessment in hamsters

The frequency of mortality and illness signs, including rales, ocular exudates, nasal discharge, and morbidity were observed at days 1, 2, and 3 post challenge with each of the differently passaged viruses. These frequencies were used as indicators of H9N2 virus adaptability to hamster host cells.

\section{Gross lesions}

Experimental and control hamsters were sacrificed with $\mathrm{CO}_{2}$ three days following the viral incubation period. Gross lesions resulting from the three differently passaged H9N2 viruses in hamsters were observed and recorded for each animal, namely tracheitis and lung congestion. These observations were used as additional indicators of the H9N2 virus's pathogenic adaptation to mammalian cells of hamsters. Tracheas and lungs were each individually removed aseptically and cut into two sections. One section was fixed in $10 \%$ formalin for histopathologic observations, while the second section was used for
H9N2 viral detection by the presumptive HA test [5].

Histopathology

The histopathological studies on collected organs of experimental and control hamsters included the use of the $10 \%$ formalin fixed tissues that were sectioned at $4 \mu \mathrm{m}$ thickness, followed by hematoxylin and eosin staining. Microscopic observations included the recording of tracheal deciliation, mucosal hypertrophy, goblet cell degeneration, mucus accumulation, and heterophil infiltration in four tracheal sections per bird. The observations were done in four microscopic fields per tissue section, located at 2, 4, 8, and 10 o'clock positions. These microscopic lesions were additional indicators of the H9N2 viral pathogenic adaptability to the mammalian cells of hamsters. A score of 1 was assigned for each of the following tracheal tissue changes: deciliation, mucosal hypertrophy, goblet cell degeneration, and mucus accumulation. A score of 0 was assignedto the absence of tracheal changes. The average score of four observed microscopic fields per tissue section in each of the 10 hamsters per treatment was used in statistical analysis. The same procedure was followed to compare the frequencies of mucus accumulation in the air ducts of the lungs. The cumulative heterophil count in 16 fields (4 fields per each of the four tissue sections of each respiratory organ) was recorded.

\section{Amplification and sequencing of specific H9N2 genome segments}

Different sets of primers were used for the amplification and nucleotide sequencing of the HA and of neuraminidase (NA) stalk genes of P0, P1, P2, and P3 H9N2 viruses (Table 1).

Viral RNA was extracted from tracheal and lung homogenates using the QIAamp Viral RNA Mini Kit (Qiagen, Hilden, Germany). The extracted RNA from all passages was adjusted to $100 \mathrm{ng}$ per $50 \mu \mathrm{L}$ of the reaction mixture. The RNA was amplified by reverse

Table 1. Primers used in RT-PCR amplification of HA and N2 stalk genes of the experimental H9N2 viruses

\begin{tabular}{|c|c|c|c|c|c|}
\hline Primer set & $\begin{array}{l}\text { Target } \\
\text { gene }\end{array}$ & $\begin{array}{l}\text { Nucleotide } \\
\text { position }\end{array}$ & $\begin{array}{c}\text { Expected } \\
\text { length of the } \\
\text { amplicon (bp) }\end{array}$ & $\begin{array}{c}\text { Host cells of } \\
\text { the virus }\end{array}$ & Reference \\
\hline $\begin{array}{l}\text { Hu1: 5'-TAT GGG GCA TAC AYC AYC C-3' } \\
\text { Hu2c: 5'-TCT ATG AAC CCW GCW ATT GCT CC-3' }\end{array}$ & H9 & $592-1078$ & 486 & Avian & $\begin{array}{c}\text { Banks et } \\
\text { al., 2000 } \\
{[23]}\end{array}$ \\
\hline $\begin{array}{l}\text { Hum F: 5'-TTG CAC CAC ACA GAG CAC AAT-3' } \\
\text { Hum R: 5'-TGA TGT ATG CCC CAC AT GAA-3' }\end{array}$ & H9 & $143-575$ & 432 & $\begin{array}{l}\text { Humans, } \\
\text { swine, avian }\end{array}$ & $\begin{array}{l}\text { Peiris et } \\
\text { al., } 1999 \\
\text { [24] }\end{array}$ \\
\hline
\end{tabular}


transcription-polymerase chain reaction (PCR), using a One-Step RT-PCR Kit (Qiagen, Hilden, Germany).

The resulting DNA amplicons were subjected to electrophoresis and visualized in $2 \%$ agarose gel using ethidium bromide staining. The DNA amplicon was excised from the gel and purified with the QIAquick Gel Extraction Kit (Qiagen, Hilden, Germany). The nucleotide sequence of the successfully amplified HA and NA stalk of the experimental viruses recovered from each of the two respiratory organs of the hamsters was determined by the 3100 AvantGenetic Analyzer ABI PRISM (Applied Biosystems Hitachi, Foster City, USA), and by the inclusion of the reverse primers for avian and mammalian $\mathrm{H} 9-\mathrm{HA}(\mathrm{Hu} 2 \mathrm{c}$ and HumR, respectively) and for NA stalk (NAR primer).

The amino acid coding by the nucleotide sequencesof the original (P0) and the differently passaged isolates of $\mathrm{H} 9 \mathrm{~N} 2$ ( $\mathrm{P} 1, \mathrm{P} 2$, and $\mathrm{P} 3$ ) were determined and compared using the program of the NCBI website, known as the Basic Local Alignment Search Tool (BLAST version 2.2.15) (www.ncbi.nlm.nih.gov).

\section{Statistics}

The frequencies of mortality and morbidity signs, indicators of avian influenza viral pathogenic adaptability to mammalian tissues of hamsters, observed at days 1,2 , and 3 post challenge, were compared among the controls and challenged animals using the Chi-square test. The same test was applied to compare other indicators of the viral pathogenic adaptability, namely the frequencies of detection of the differently passaged viruses from the tracheas and lungs of the experimental animals, and the frequencies of gross lesions in the two respiratory tissues of experimental hamsters three days post challenge. The frequency of other pathogenic adaptability indicators (microscopic lesions) were compared using one-way ANOVA and Tukey's test. Statistical analysis was performed using the Statistical Package for the Social Sciences program version 18 (SPSS Inc., Chicago, USA).

\section{Results}

Pathogenic adaptability assessment in hamsters

Mortality and morbidity

No mortalities were recorded among the control hamsters and those challenged with $\mathrm{P} 1, \mathrm{P} 2$, or P3 viruses. Moreover, no signs of rales or ocular exudates were observed during the three consecutive days post challenge with the differently passaged H9N2 viruses. The morbidity sign was not observed among P1, P2, and P3challenged hamsters at one or two days post challenge. In addition, the frequency of morbidity, observed at day three post challenge, was not significantly different among P1, P2, and P3 hamsters $(2 / 10,2 / 10$, and $1 / 10$, respectively; $p>0.05)$ (Table 2$)$.

The frequency of nasal discharge increased significantly in P3challenged hamsters, in comparison to $\mathrm{P} 1$ and $\mathrm{P} 2$ hamsters, rising from $1 / 10$ in day one to respective frequencies of $6 / 10$ and $4 / 10$ in days two and three post challenge $(\mathrm{p}<0.05)$.

\section{$\underline{\text { Gross lesions }}$}

In studying the gross lesions caused by each of the three differently passaged strains, experimental $(\mathrm{n}=$ 10) and control hamsters $(n=10)$ were distributed in four separate cages, with five hamsters per cage. The experimental and the control hamsters were kept in two separate isolation rooms. The frequencies of the gross lesions were insignificantly different among hamsters challenged with either $\mathrm{P} 1, \mathrm{P} 2$, or $\mathrm{P} 3$ viruses (Table 3).

Presumptive and confirmative H9N2 viral detection in hamsters' respiratory organs.

The presumptive H9N2 viral detection by observation of the hemagglutination reaction of tracheal and lung homogenate against chicken red blood cells (RBC) is shown in Table 4. The frequency of viral presumptive detection dropped to $0 / 10$ in tracheas and 4/10 in lungs of P2challenged hamsters, then rose significantly to $5 / 10$ and $9 / 10$, respectively, in the tracheas and lungs of P3challenged hamsters ( $p$ $<0.05)$. The RT-PCR amplification of the matrix gene of the infecting viruses used in this work confirmed the presence of influenza viruses in the lungs and tracheas of the experimental hamsters, yielding a 265 bp amplicon, except for the pooled tracheas of hamsters challenged with the $\mathrm{P} 2$ virus.

The RT-PCR results for the detection of H9N2 virus in tissues of challenged hamsters were in agreement with those obtained by the HA test, revealing an absence of HA activity by the tracheal homogenate of P2-challenged hamsters (Table 4). 
Table 2. Frequency of hamsters with specific morbidity signs three days post H9N2 virus challenge*

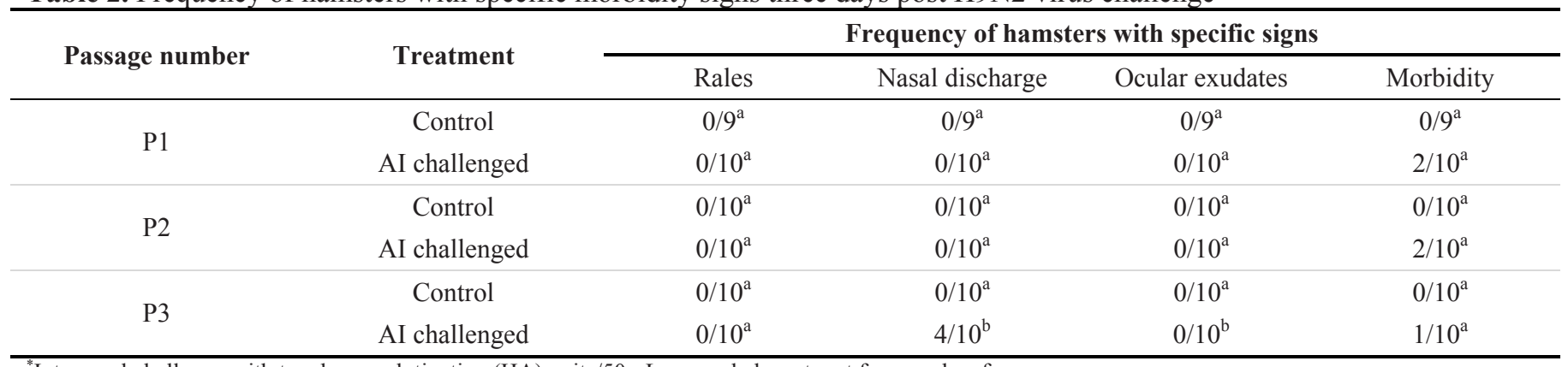

"Intranasal challenge with two hemagglutination (HA) units $/ 50 \mu \mathrm{L}$ per male hamster at four weeks of age

${ }^{a-b}$ Frequencies in columns with different alphabetic superscripts are significantly different $(p<0.05)$

Table 3. Frequency of hamsters with specific gross lesions at three days post H9N2 challenge ${ }^{*}$

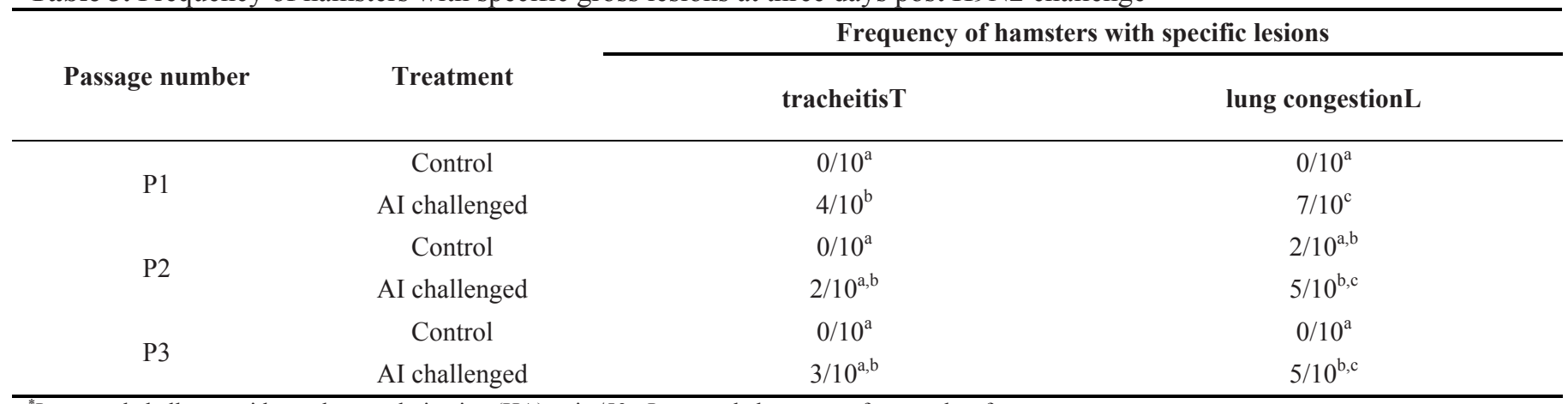

*Intranasal challenge with two hemagglutination (HA) units $/ 50 \mu \mathrm{L}$ per male hamster at four weeks of age

${ }^{\mathrm{a}-\mathrm{c}}$ Frequencies in columns with different alphabetic superscripts are significantly different $(\mathrm{p}<0.05)$

Table 4. Frequency of presumptive ${ }^{*}$ viral detection in tracheas and lungs of the experimental hamsters three days post H9N2 virus challenge ${ }^{* *}$ using the hemagglutination test

\begin{tabular}{|c|c|c|c|}
\hline \multirow{2}{*}{ Passage number } & \multirow{2}{*}{ Treatment } & \multicolumn{2}{|c|}{ Frequency of presumptive viral detection in organs } \\
\hline & & Trachea & Lung \\
\hline P1 & Control & $0 / 9^{a}$ & $0 / 9^{a}$ \\
\hline \multirow{2}{*}{$\mathrm{P} 2$} & Control & $0 / 10^{\mathrm{a}}$ & $0 / 10^{\mathrm{a}}$ \\
\hline & AI challenged & $0 / 10^{\mathrm{a}}$ & $4 / 10^{\mathrm{b}}$ \\
\hline P3 & AI challenged & $5 / 10^{\mathrm{b}}$ & $9 / 10^{\mathrm{c}}$ \\
\hline
\end{tabular}

"Presumptive detection was based on hemagglutination (HA) test performed on individual organs' homogenate against $0.5 \%$ of chicken RBC

${ }^{* *}$ Intranasal challenge with two hemagglutination (HA) units $/ 50 \mu \mathrm{L}$ per male hamster at four weeks of age

${ }^{\mathrm{a}-\mathrm{c}}$ Frequencies in columns with different alphabetic superscripts are significantly different $(\mathrm{p}<0.05)$ 


\section{Histopathology}

The frequencies of hamsters showing microscopic lesions in their tracheas and lungs are presented in Table 5. A non-significant increase in the average percentage of microscopic fields showing goblet cells degeneration $(26.2 \%)$ and mucus accumulation $(11.2 \%)$ was observed in the tracheas of P3challenged hamsters in comparison to their respective observations in P1- $(20.1 \%$ and 6.9\%) and P2challenged hamsters $(23.1 \%$ and $10.6 \%$, respectively) ( $\mathrm{p}>0.05)$.

In addition, a non-significant increase was observed in the average percentage of lung tissue fields showing mucus accumulation (26.3\%) and hyperplasia $(25.6 \%)$ in the lung parenchyma of P3challenged hamsters in comparison to their respective observation in $\mathrm{P} 1$ (25.7\% and $16.7 \%)$ and P2challenged hamsters $(23.0 \%$ and $16.5 \%)(\mathrm{p}>0.05)$.

\section{Amplification and sequencing of the H9N2-specific genome}

PCR amplification of the HA1 gene in pools of tracheas and lungs obtained from P1, P2, and P3 hamsters using primers $\mathrm{Hu} 1$ and $\mathrm{Hu} 2 \mathrm{c}$ [23], failed; the HA gene of the original P0 virus, however, was successfully amplified, resulting in an amplicon situated at 486 bp size.
The primers reported by Peiris et al. [24] for amplification of the H9-HA gene part of swine, avian, and human H9N2 viruses (HumF and HumR), were able to amplify successfully triplicate runs of the H9HA gene at position 143 to 575 of $\mathrm{P} 0$ and $\mathrm{P} 3$ viruses recovered from tracheas and lungs, and of $\mathrm{P} 1$ and $\mathrm{P} 2$ viruses recovered only from lung tissues of challenged hamsters (P1L and P2L, respectively).The sequencing was restricted to the amino acid position 50 to 165 , revealing a $100 \%$ similarity in the HA sequenced region of $\mathrm{P} 0, \mathrm{P} 1 \mathrm{~L}, \mathrm{P} 2 \mathrm{~L}$, and $\mathrm{P} 3 \mathrm{H} 9 \mathrm{~N} 2$ viruses. The sequence had a $99 \%$ similarity to that of $\mathrm{H} 9 \mathrm{~N} 2$ viruses isolated from Israeli chickens, and a 93\% to $95 \%$ similarity to that of two human H9N2 isolates (Table 6).

Amplification of the N2 stalk using NAF and NAR primers was successfully obtained in the P0 and P3 viruses recovered from the lungs of the experimental animals, yielding an amplicon of $1270 \mathrm{bp}$. A common amino acid difference was obtained at position 46 of the $\mathrm{N} 2$ stalk of $\mathrm{P} 0$ and $\mathrm{P} 3$, in which the arginine (R) in $\mathrm{P} 0$ was replaced by proline $(\mathrm{P})$ in $\mathrm{P} 3$ of the lungs (Table 7).

Table 5. Histopathologic lesions by H9N2 virus in two respiratory organs of hamsters three days post challenge* with the differently passaged viruses.

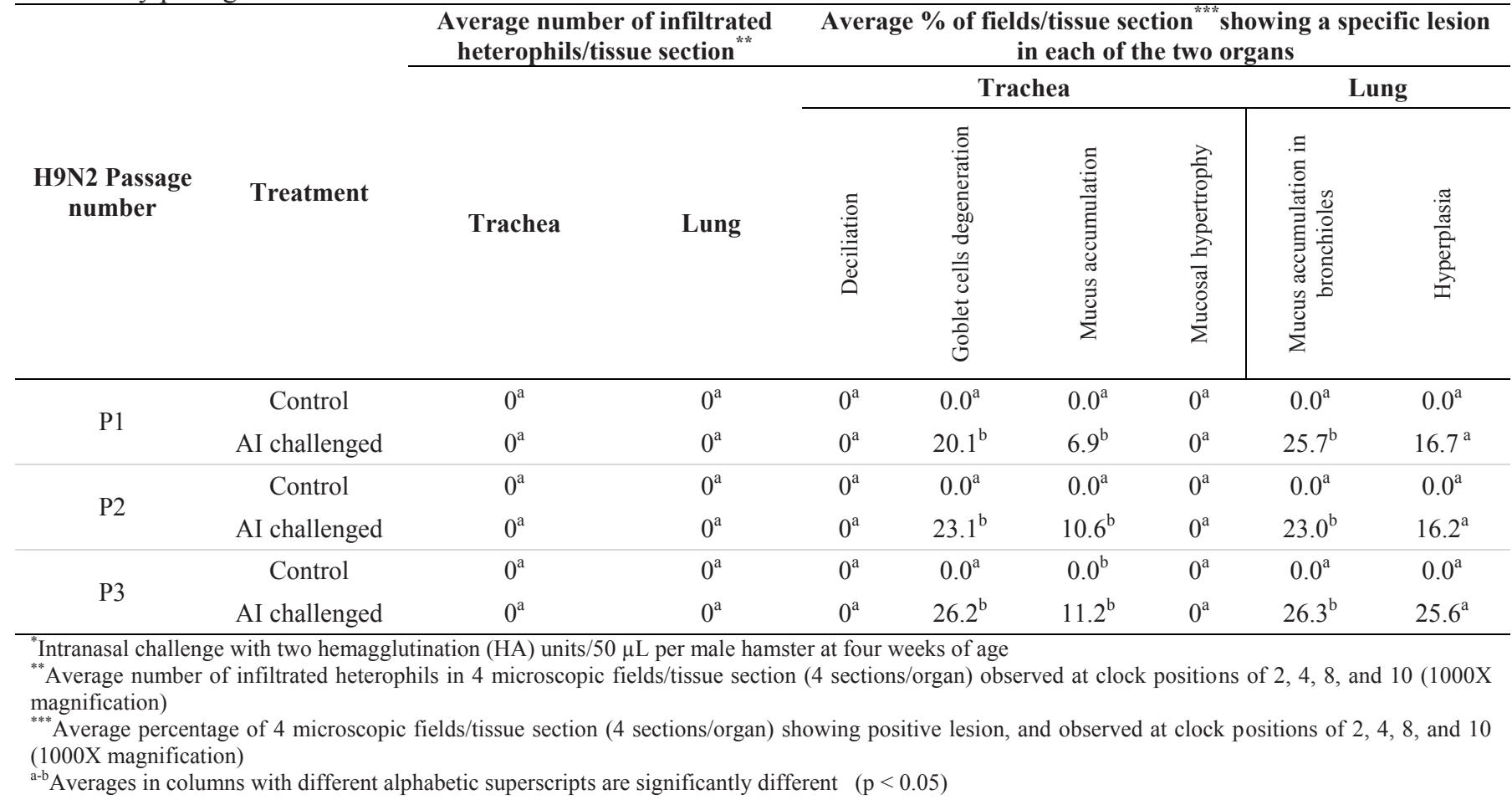


Table 6. Comparison of the analyzed amino acid sequences of a part of the HA gene of the differently passaged H9N2 viruses to two reported human isolates (A/HK/1073/99 and A/HK/1074/99) (position 50-165)

Experimental ${ }^{*}$

and reported

\section{Amino acid sequence of HA from a.a position 50 to $165^{* * * *}$}

P0, P1L, P2L, 50

P3L, and P3T

A/HK/1073/99

A/HK/1074/99

"P0L original H9N2 virus isolated from a broiler; P1L, P2L, and P3L: experimental H9N2 strains recovered from lungs of hamsters challenged respectively with one, two, and three times passaged viruses;

P3T: experimental H9N2 viruses recovered from tracheas of hamsters challenged with a three times passaged virus

${ }^{* *} \mathrm{~A} / \mathrm{HK} / 1073 / 99$ and A/HK/1074/99 H9N2 strains were isolated in Hong Kong on 5 March 1999 from nasopharyngeal aspirates of two patients with mild influenza namely a 4-year-old girl and a 13-monthold girl, respectively

${ }^{* * *}$ Each dot indicates the presence of the same amino acid found in the original P01 virus. The presence of an alphabet letter in the place of a dot indicates a point mutation (replacement by a different amino acid).

Table 7. Comparison of the analyzed amino acid sequences of a part of the neuraminidase stalk of the differently passaged avian H9N2 viruses in hamsters to the two reported human isolates from Hong Kong (A/HK/1073/99 and A/HK/1074/99) (position 32-104)

\begin{tabular}{|c|c|}
\hline Experimental $^{*}$ and reported ${ }^{* *}$ H9N2 viruses & Amino acid sequence of NA stalk from position 32 to $104^{* * *}$ \\
\hline \multirow{2}{*}{ P01 } & 32 \\
\hline & TMTLHFKQNDCTNPRNNQVVPCGP I LIERNITEIVHLNNTT IEKENCPKVAEYKNWLKPQCQITGFAPFSKDN \\
\hline P02 & 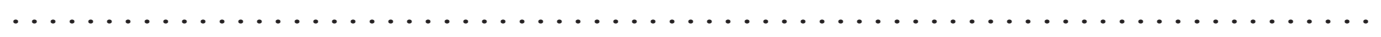 \\
\hline $\mathrm{P} 03$ & 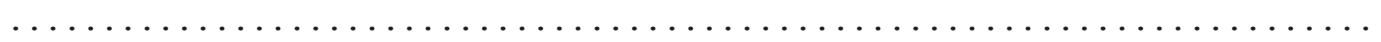 \\
\hline P3L1 & 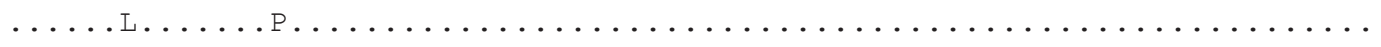 \\
\hline P3L2 & 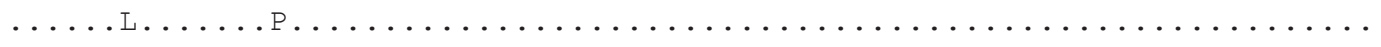 \\
\hline P3L3 & 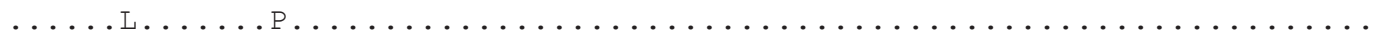 \\
\hline $\mathrm{A} / \mathrm{HK} / 1073 / 99$ & 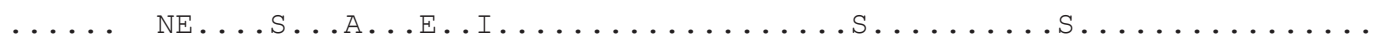 \\
\hline $\mathrm{A} / \mathrm{HK} / 1074 / 99$ & 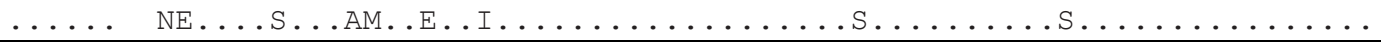 \\
\hline
\end{tabular}

"P01, P02, P03: original avian H9N2 virus' sequences in triplicate; P3L1, P3L2, and P3L3: experimental H9N2 viruses recovered in triplicates of pooled lung homogenates of hamsters challenged with the three times passaged virus

${ }^{* *} \mathrm{~A} / \mathrm{HK} / 1073 / 99$ and A/HK/1074/99 viruses were isolated in Hong Kong on 5 March 1999 from nasopharyngeal aspirates of two patients with mild influenza, namelya 4-year-old girl and a 13-month-old girl, respectively

${ }^{* *}$ Each dot indicates the presence of the same amino acid found in the original P01 virus. The absence of a dot, in a defined position, indicates the presence of an amino acid deletion at that position. The presence of an alphabet letter in the place of a dot indicates a point mutation (replacement by a different amino acid). 


\section{Discussion}

The results of this study demonstrated the low pathogenicity of the original avian influenza H9N2 virus and the differently passaged H9N2 viruses, as deduced from the absence of mortality and the low morbidity among the differently challenged hamsters [25].

The nasal discharge signs during the incubation period of P3 viruses in hamsters rose three days post challenge. This is in agreement with the studied incubation period reported in the works of Newby et al. [13] and Deng et al. [26]. However, the impact of three H9N2 virus passages in hamsters was not prominent compared to the observation of high mortality in mice that were challenged with 10 passaged viruses [27]. This could be due to differences in the number of passages and/or the difference in the susceptibility of the mammalian species used in the two studies.

The frequency of lung congestion in challenged hamsters was higher than that of tracheitis, indicating a higher tropism of the H9N2 viruses to lung cells compared to ciliated tracheal cells $[13,28]$. The work of Newby et al. 2006 [13] proved that type A influenza viruses infect primarily non-ciliated cells of hamsters, expressing both $\alpha-2,3$ and $\alpha-2,6$ SA receptors, specifically at one and two days following infection. It is worth noting that the ciliated cells show a reduction in the amount of $\alpha-2,3 \mathrm{SA}$ in comparison to non-ciliated cells. However, these findings may vary according to the host species used for challenge. For instance, previous literature reported that the tracheal tissue is the preferred infection site for H9N2 viruses in avian [25,29,30] and equine [31] species, due mainly to the prevalence of $\alpha-2,3 \mathrm{SA}$ receptors in their tracheal cells.

The H9N2 viruses were presumptively detected in all tracheas and lungs of P1challenged hamsters, which encourages the use of this animal model for studying the pathogenic adaptation of avian influenza viruses to mammals [13]. However, this observed pathogenic adaptation of avian influenza raises a concern about the mixing of different animal species in farm settings, which is widely the situation in many of the developing countries $[32,33]$.

The third passage of the H9N2 virus seems to restore the viral tropism of the H9N2 virus to the lungs more than to the trachea, proving a preferred tropism of these viruses to non-ciliated alveolar cells of the lungs that are richer in $\alpha-2,3$ and $\alpha-2,6$ SA receptors [13].
These findings point at the future possible role of the original and multiply passaged H9N2 viruses in human pandemics, since the replication of H9N2 AI viruses in hamsters' lungs is highly correlated to their virulence in humans $[34,28]$. In this context, human $\mathrm{A} / \mathrm{HK} / 1073 / 99 \mathrm{H} 9 \mathrm{~N} 2$ viruses were recovered from $100 \%$ of the lungs of hamsters three days following the challenge with a dose of $10^{2.3} \mathrm{EID}_{50}$. Accordingly, the H9N2 virus replication in hamsters' lungs could relate to its pathogenic adaptation to human hosts [28].

The absence of heterophils infiltration in the tracheal mucosal layer and lung parenchyma and the absence of epithelial cell deciliation and thickening of mucosal layer in tracheal cuts of the challenged animals are indicators of the insignificant damage, mainly to the tracheal tissue by the avian H9N2 virus, and its inability to form necrosis in this organ $[35,36]$. Advanced tissue damage of virulent AI viruses, including H9N2 viruses that were previously reported in literature, included desquamation of the ciliated epithelium of tracheo-bronchial airways, mononuclear cell inflammatory infiltrates, and necrosis of lung and trachea tissue in avian species and mammals [37,38].

The insignificant tissue changes due to viral passaging observed in this work are mainly hindered by the interspecies pathogenic adaptability and the low number of viral passaging in hamsters. However, other studies have reported that a tenfold lung-to-lung passage of a swine isolate (SW/HK/9/98-MA H9N2) in mice resulted in an increase of virulence of this virus towards murine respiratory cells and was associated with high mortality among the experimental animals [27]. On the contrary, the human H9N2 strain pathogenicity was reduced by passaging it in hamsters and MDCK cells, thus emphasizing the role of the type of host cells in the level of pathogenic adaptability of the passaged $\mathrm{H} 9 \mathrm{~N} 2$ viruses.

Regarding mutations, the failure of the amplification of the HA gene in pools of tracheas or lungs from P1, P2, and P3 hamsters by PCR using Hu1 and $\mathrm{Hu} 2 \mathrm{c}$ primers indicates the possibility of a significant mutation occurrence at the complementary sequences of the used primers, namely at nucleotide positions 592-610 and 1055-1078. However, the successful amplification of the HA gene of the original $\mathrm{P} 0$ virus confirms the specificity of the used primers to the avian H9N2 virus, as cited in the literature [23].

In addition, mutations could have occurred at certain complementary sequences to the Humf and HumR primers in the H9-HA gene of P1 viruses recovered from the tracheas of challenged hamsters (P1T). These mutations could have prohibited the 
primers' annealing and the subsequent amplification. These results could indicate the presence of two different populations of $\mathrm{H} 9 \mathrm{~N} 2$ viruses in the lungs and tracheas of the challenged hamsters due to the presence of different receptors in these two tissues [13]. Consequently, this part of the HA gene seems unsuitable for tracking amino acid changes that could be responsible for an increased pathogenic adaptability to mammalian cells. This finding suggests the need for future investigation of the nucleotide sequence variability at the complementary sequences to the HumF and HumR primers of the HA gene; significant mutations in complementary sequences of HA gene to avian or mammalian primers (HumF and HumR) could lead to a failure in PCR amplification of this specific HA gene segment, as demonstrated in the tracheas of P1 hamsters that showed the presence of the H9N2 matrix gene. In the future, it is worth looking at the whole HA gene sequence and at a series of modifications in the viral internal genes that could dictate the adaptation of the avian influenza H9N2 virus to the mammalian cell.

The H9-HA amino acid sequence of P0, P3, P1L, and $\mathrm{P} 2 \mathrm{~L}$ viruses had a $99 \%$ similarity to that of the H9N2 viruses isolated from Israeli chickens, namely A/avian/Israel/584/2005, A/chicken/Israel/178/2006, A/chicken/Israel/1376/2003,A/chicken/Israel/1966/20 04, A/chicken/Israel/29/2005, and $\mathrm{A} /$ chicken/Israel/1475/2003. However, the similarity dropped to a respective $93 \%$ and $95 \%$ when the HA sequence was compared to that of the two human $\mathrm{H} 9 \mathrm{~N} 2$ isolates, namely the $\mathrm{A} / \mathrm{HK} / 1073 / 99$ and A/HK/1074/99 recovered in Hong Kong [1]. The HA amino acid sequence of the multiply passaged viruses, between positions 50 to 165 , were stable, and showed a higher similarity to the avian $\mathrm{H} 9 \mathrm{~N} 2$ virus.

Amplification of the N2 stalk was successful for P0 and P3 viruses recovered from the lungs of experimental animals. The passaging and adaptation of the H9N2 virus to mammalian cells led to mutations at the primer level of the N2 gene, positions 25-44 and 1277-1296 in P1 and P2 H9N2 viruses. Sequencing revealed a similarity percentage of the $\mathrm{N} 2$ stalk of $\mathrm{P} 0$ (avian) and P3 (mammalian) virus of 97.3\%, while both $\mathrm{P} 0$ and $\mathrm{P} 3$ viruses had $\mathrm{N} 2$ gene with $86 \%$ and $85 \%$ similarity to the two human isolates $\mathrm{A} / \mathrm{HK} / 1073 / 99$ and $\mathrm{A} / \mathrm{HK} / 1074 / 99$, respectively.

However, it has been reported in the literature that the adaptation of the H9N2 virus to mammalian cells includes a deletion of two amino acids from the N2 stalk, namely at positions 38 and 39 , as reported in strains HK/1073/99 and HK/1074/99 [21]; these deletions were not present in the N2 stalk of the P0 and P3 viruses. More serial passages could lead to higher pathogenicity as a result of the possible deletion of the two amino acids at positions 38 and 39 in the NA stalk. This hypothesis will be dealt with in a future investigation.

The replacement of arginine at amino acid position 46 of the N2 stalk of the P0 avian isolate by the proline in P3 of hamsters' lungs could be of significance in affecting the pathogenic adaptability of the H9N2 virus. The proline possesses a neutral side chain instead of a positively charged one, which might affect the configuration of the $\mathrm{N} 2$ stalk of the P3 H9N2 virus [39], thus raising concerns about its impact on public health. The role of these mutations in the N2 stalk of the H9N2 virus in mammalian species needs further investigation, which can lead to the development of efficacious vaccines against this threatening zoonotic etiology of avian influenza.

\section{Acknowledgements}

We are grateful to the University Research Board of the American University of Beirut (AUB) for funding this research. We are also thankful to Professor Nahla Hwalla, Dean of the Faculty of Agricultural and Food Sciences/AUB, for assisting in upgrading the facilities where this research was conducted. Sincere thanks are addressed to the administration of Université de Technologie de Compiègne, Institut Polytechnique La Salle Beauvais, and Université de Picardie-Jules Verne in France, for cooperating on this study.

\section{References}

1. Lin YP, Shaw M, Gregory V, Cameron K, Lim W, Klimov A, Subbarao K, Guan Y, Krauss S, Shortridge K, Webster R, Cox N, Hay A (2000) Avian-to-human transmission of H9N2 subtype influenza A viruses: relationship between H9N2 and H5N1 human isolates. Proc Natl Acad Sci 97: 9654-9658.

2. Perez DR, Lim W, Seiler JP, Yi G, Peiris M, Shortridge KF, Webster RG (2003) Role of quail in the interspecies transmission of H9 influenza A virus: Molecular changes on HA that correspond to adaptation from ducks to chickens. J Virol 77: 3148-3156.

3. Sun Y, Qin K, Wang J, Pu J, Tang Q, Hu Y, Bi Y, Zhao X, Yang H, Shu Y, Liu J (2011) High genetic compatibility and increased pathogenicity of reassortants derived from avian H9N2 and pandemic H1N1/2009 influenza viruses. Proc Natl Acad Sci 108: 4164-4169.

4. Govorkova EA, Rehg JE, Yen HL, Guan Y, Peiris M, Nguyen TD, Hanh TH, Puthavathana P, Long HT, Buranathai C, Lim W, Webster R, Hoffmann E (2005) Lethality to ferrets of $\mathrm{H} 5 \mathrm{~N} 1$ influenza viruses isolated from humans and poultry in 2004. J Virol 79: 2191-2198.

5. Liu JH, Okazaki K, Shi WM, Kida H (2003) Phylogenetic analysis of hemagglutinin and neuraminidase genes of H9N2 virus isolated from migratory ducks. Virus Genes 27: 291296. 
6. Mok C, Yen H, Yu M, Yuen K, Sia S, Chan M, Qin G, Tu W, Peiris J (2011) Amino acid residues 253 and 591 of the PB2 protein of avian influenza virus A H9N2 contributes to mammalian pathogenesis. J Virol 85: 9641-9645.

7. Zhang P, Tang Y, Liu X, Peng D, Liu W, Liu H, Lu S, Liu X (2008) Characterization of H9N2 influenza viruses isolated from vaccinated flocks in an integrated broiler chicken operation in eastern China during a 5 year period (19982002). J Gen Virol 89: 3102-3112.

8. Banet-Noach C, Panshin A, Golender N, Simanov L, Rozenblut E, Pokamunski S, Pirak M, Tendler Y, Garcia M, Gelman B, Pasternak R, Perk S (2007) Genetic analysis of nonstructural genes (NS1 and NS2) of $\mathrm{H} 9 \mathrm{~N} 2$ and $\mathrm{H} 5 \mathrm{~N} 2$ virus recently isolated in Israel. Virus Genes 34: 157-168.

9. Barbour EK, Sagherian VK, Sagherian NK, Dankar SK, Jaber LS, Usayran NN, Farran MT (2006) Avian Influenza outbreak in poultry in the Lebanon and transmission to neighbouring farmers and swine. Vet Ital 42: 13-21.

10. Barbour EK, Shaib HA, Rayya EG (2007) Reverse transcriptase-polymerase chain reaction-based surveillance of type A influenza viruses in wild and domestic birds of the Lebanon. Vet Ital 43: 33-41.

11. Guo YJ, Krauss S, Senne DA., Mo IP, Lo KS, Xiong XP, Norwood M, Shortridge KF, Webster RG, Guan Y (2000) Characterization of the pathogenicity of members of the newly established H9N2 influenza virus lineages in Asia. Virology 267: 279-288.

12. Ilyushina NA, Rudneva IA, Gambaryan AS, Kaverin NV (2004) Changes in the affinity of the hemagglutinin to sialic receptors in the $\mathrm{H} 5$ and $\mathrm{H} 9$ influenza virus escape mutants. Int Congr Ser 1263: 773-776.

13. Newby CM, Rowe RK, Pekosz A (2006) Influenza A virus infection of primary differentiated airway epithelial cell cultures derived from Syrian golden hamsters. Virology 354: 80-90.

14. Thongratsakul S, Suzuki Y, Hiramatsu H, Sakpuaram T, Sirinarumitr T, Poolkhet C, Moonjit P, Yodsheewan R, Songserm T (2010) Avian and human influenza A virus receptors in trachea and lung of animals. Asian Pac J Allergy Immunol 28: 294-301.

15. Bi J, Deng G, Dong J, Kong F, Li X, Xu Q, Zhang M, Zhao L, Qiao J (2010) Phylogenetic and molecular characterization of H9N2 influenza isolates from chickens in northern China from 2007-2009. PLoS One 5: e13063.

16. Gambaryan AS, Tuzikov AB, Pazynina GV, Webster RG, Matrosovich MN, Bovin NV 2004) H5N1 chicken influenza viruses display a high binding affinity for Neu5Ac[alpha]23Gal[beta]1-4(6-HSO3) GlcNAc-containing receptors. Virology 326: 310-316.

17. Kim JA, Ryu SY, Seo SH (2005) Cells in the respiratory and intestinal tracts of chickens have different proportions of both human and avian influenza virus receptors. J Microbiol 43: 366-369.

18. Matrosovich M, Tuzikov A, Bovin N, Gambaryan A, Klimov A, Castrucci MR, Donatelli I, Kawaoka Y (2000): Early Alterations of the Receptor-Binding Properties of H1, H2, and H3 Avian Influenza Virus Hemagglutinins after their Introduction into Mammals. J Virol 74: 8502-8512.

19. Matrosovich MN, Matrosovich TY, Gray T, Roberts NA, Klenk HD (2004) Human and avian influenza viruses target different cell types in cultures of human airway epithelium. Proc Natl Acad Sci 101: 4620-4624.
20. Kayali G, Barbour E, Dbaibo G, Tabet C, Saade M, Shaib H, Debeauchamp J, Webby R (2011) Evidence of Infection with H4 and H11 Avian Influenza Viruses among Lebanese Chicken Growers. PLoS ONE 6: e26818.

21. Webby R, Kayali G, Barbour E, Dbaibo G, Saade M, Tabet C, Shaib HA, Debeauchamp J (2011) Influenza A virus (A/quail/Lebanon/273/2010(H9N2)) hemagglutinin (HA) gene, complete cds, GenBank accession number: CY093096.1. Pubmed. http://www.ncbi.nlm.nih.gov/nuccore/CY093096.1.

22. Swayne DE, Senne DA, Suarez DL (2008): Avian influenza. In Dufour-Zavala L, Swayne DE, Glisson JR, Pearson JE, Reed WM, Jackwood MW, Woolcock PR, editors. A Laboratory Manual for the Isolation and Identification of Avian Pathogens. Kennett Square, PA: American Association of Avian Pathologists. 128-134.

23. Banks J, Speidel EC, Harris PA, Alexander DJ (2000) Phylogenetic analysis of influenza A viruses of H9 haemagglutinin subtype. Avian Pathol 29: 353-360.

24. Peiris M, Yam WC, Chan KH, Ghose P, Shortridge KF: Influenza A H9N2: Aspects of laboratory diagnosis. J Clin Microbiol 37: 3426-3247.

25. Pantin-Jackwood MJ, Swayne DE (2009) Pathogenesis and pathobiology of avian influenza virus infection in birds. Rev Sci Tech OIE 28: 113-136.

26. Deng Y, Zhang K, Tan W, Wang Y, Chen H, Wu X, Ruan L (2009) A recombinant 370 DNA and vaccinia virus primeboost regimen induces potent long-term T-cell 371 responses to HCV in BALB/c mice. Vaccine 27: 2085-2088.

27. Kaverin NV, Rudneva IA, Ilyushina NA, Lipatov AS, Krauss S, Webster RG (2004) Structural differences among hemagglutinins of influenza A virus subtypes are reflected in their antigenic architecture: analysis of $\mathrm{H} 9$ escape mutants. J Virol 78: 240-249.

28. Saito T, Lim W, Tashiro M (2004) Attenuation of a human H9N2 influenza virus in mammalian host by reassortment with an avian influenza virus. Arch Virol 149: 1397-1407.

29. Shaib HA, Cochet N, Ribeiro T, Abdel Nour AM, Nemer G, Barbour EK (2010) Impact of embryonic passaging of H9N2 virus on pathogenicity and stability of HA1-amino acid sequence cleavage site. Med Sci Monit 16: 333-337.

30. Swayne DE, Halvorson DA (2008) Influenza. In Saif YM, Barnes HJ, Fadly AM, Glisson JR, McDougald LR, Swayne DE, editors. Diseases of Poultry. Ames, Iowa: Iowa State University Press. 153-184.

31. Daly JM, Yates RJ, Browse G, Swann Z, Newton JR, Jessett D, Davis-Poynter N, Mumford JA (2003) Comparison of hamster and pony challenge models for evaluation of effect of antigenic drift on cross protection afforded by equine influenza vaccines. Equine Vet J 35: 458-462.

32. FAO Recommendations on the prevention, control and eradication of Highly Pathogenic Avian Influenza (HPAI) in Asia. FAO Position Paper. Available: http://web.oie.int/eng/AVIAN_INFLUENZA/FAO\%20recom mendations\%20on\%20HPAI.pdf. 2013.

33. Yu H, Zhou YJ, Li GX, Ma JH, Yan LP, Wang B, Yang FR, Huang M, Tong GZ (2011) Genetic diversity of H9N2 influenza viruses from pigs in China: A potential threat to human health? Vet Microbiol 149: 254-261.

34. Heath AW, Addison C, Ali M, Teale D, Potter CW (1983) In vivo and in vitro hamster models in the assessment of virulence of recombinant influenza viruses. Antiviral Res 3: 241-252. 
35. Ewbank J (2008) Innate immunity. Totowa, NJ: Humana Press 458.

36. Swaggerty C, Kaiser P, Rothwell L, Pevzner Y, Kogut MH (2006) Heterophil cytokine mRNA profiles from genetically distinct lines of chickens with differential heterophil mediated innate immune responses. Avian Pathol 35: 102-108.

37. Gohrbandt S, Veits J, Breithaupt A, Hundt J, Teifke JP, Stech O, Mettenleiter TC, Stech J (2011) H9 avian influenza reassortant with engineered polybasic cleavage site displays a highly pathogenic phenotype in chicken. J Gen Virol 92: 1843-1853.

38. Taubenberger JK, Morens DM (2008) The pathology of influenza virus infections. Annu Rev Path Mech Dis 3: 499522.
39. Betts MJ, Russell RB (2003) Amino acid properties and consequences of substitution. In Barnes MR, Gray IC. Chichester, editors. Bioinformatics for geneticists. UK: John Wiley and Sons. 289.

\section{Corresponding author}

Professor Steve Harakeh

Special Infectious Agents Unit-Biosafety Level 3

King Fahd Medical Research Center, King Abdulaziz University

P.O. Box 80216, Jeddah 21589, Saudi Arabia

Phone: 00966559392266

Fax: 0096626952076

Email:sharakeh@gmail.com

Conflict of interests: No conflict of interests is declare 